\title{
Extraction and Replantation of a peri-apically infected tooth
}

\author{
Dennis Flanagan ${ }^{1}$ \\ ${ }^{1}$ University of Applied Sciences and Arts of Southern Switzerland - Lugano Campus
}

October 19, 2021

\begin{abstract}
An infected tooth that may be deemed unrestorable and may be salvaged by atraumatic removal, an in-hand apicoectomy and retrograde seal, then replantation. Extraction, placing an apical seal and replantation of teeth is not new, nonetheless, clinicians may need to be reminded of this procedure.
\end{abstract}

Extraction and Replantation of a Peri-Apically Infected Tooth INTRODUCTION

The advent of dental implants has saved many patients from compromised oral function. Nonetheless, the astute clinician should not abandon treatments that have been successful in the past. Treatments previously deemed appropriate may still be appropriate in appropriate conditions. Some teeth may be deemed unsalvageable but with appropriate applications these deplorable teeth may be given increased longevity. This is a report of a successful extraction, apical resection, retrograde filling and intentional replantation of a maxillary left second premolar (1).

\section{CASE REPORT}

A 44-year-old female presented by referral for extraction of the maxillary left second premolar tooth (\#13) with subsequent implant placement. The medical history was unremarkable. After an oral exam, radiographs and a discussion of options, the tooth was deemed potentially salvageable with an in situ or out-of-socket retrograde procedure. The patient opted for an extraction, out-of-socket apicoectomy and retrograde apical restoration and replantation (Fig. 1).

After informed consent the tooth was locally anesthetized with $1.6 \mathrm{cc}$ of articaine (Ketocaine). The patient was administered $2000 \mathrm{mg}$ amoxicillin orally, and chlorhexidine oral rinse. Anticipating an immediate replacement, extraction and amalgam instruments were set-up. The epithelial attachment was separated, and the coronal periodontal ligament (PDL) carefully separated using periotomes and elevators (Karl Schumacher, Des Plaines, Ill.). The tooth was slightly and carefully luxated and removed atraumatically with a \#150 forceps. The apical lesion was removed, and the apical bone debrided. The PDL was not removed. 3mm of the tooth apex was removed to insure the removal of any accessory canals (2). An apical preparation was performed and filled with amalgam (Valiant). Out-of-socket time was 22 seconds. The tooth was then replanted in its original position. The tooth was stable and immobile due to the presence of intact rigid socket bone. No flap was raised. The occlusal surface was reduced about $0.25 \mathrm{~mm}$ to minimize off axial loading during function. Nonetheless, bis-acryl facial and lingual braces were placed to minimize facial or lingual movement under function. A soft diet was recommended. Amoxicillin and chlorhexidine were prescribed. The patient was monitored weekly. After 3 weeks the tooth was not percussion tender. The braces were removed at 4 weeks, and the tooth was found to be stable and immobile (Fig. 2). The soft diet was maintained for an additional 2 weeks. After 8 weeks the tooth was deemed healed well enough to return to normal function (Fig.3). 


\section{DISCUSSION}

Removing an infected tooth and performing an in-hand apicoectomy and retrograde filling is not new (1). Nonetheless, we need to be reminded that such treatment is within the standard of care in dentistry. Such treatment may be cost effective and desirable for many patients.

The primary parameter of this modality is the careful and atraumatic removal of the tooth in question. Maintaining the osseous walls is imperative. The bone is needed for the stability of the re-implanted tooth and reattachment of the periodontal ligament (1). A facial osseous dehiscence or fenestration may prevent adequate stability for healing.

In this case, amalgam was used to seal the apex of the tooth. However, mineral trioxide aggregate (MTA) may be a better choice due to its biocompatibility and calcific barrier formation (3). MTA enhances differentiation and upregulation of osteogenic PDL cells (4). MTA can take several hours for a hard set. Unset MTA may be disturbed during reseating of the tooth in the socket and thus not seal completely, so amalgam was chosen instead.

Out-of-bone time should be less than one hour or as little time out of the socket as possible $(1,5,6)$. Nonetheless, there are reports of young patients with avulsed teeth out of the bone for much more than 1 hour $(1,6)$. However, with this procedure, if the dental team is prepared, in-hand apicoectomy and retrofilling can take place in less than 30 seconds. This short period minimizes the time where the PDL is away from its blood supply. The blood supply is ruptured indeed from the extraction but vessels, fibers and nerves may reconnect and repair if the disruption is short lived $(1,3,5)$. The socket periodontal ligament provides a blood supply for healing. The periodontal blood vessels and fibers need to reattach to the distal separated segments for appropriate healing $(1,5,7)$. This has been thought to occur if the out-of-bone time is less than 1 hour $(1,3,5)$. Thus, treatment speed is important. The less time the tooth is out of the socket and away from its blood supply, then the risk for failure is lessened $(1,5)$.

Stability in the socket is important for reconnection of the supporting, nutrient and neural tissues $(1,3,5)$. A bis-acryl brace was placed to insure stability of the tooth. The bis-acryl stent is easily placed (8). It engages the adjacent teeth inter-proximally and into undercuts for mechanical retention. In the case herein, the braces were removed after the tooth demonstrated no pain with percussion and no significant mobility.

A soft diet is needed to minimize an accidental overload of the healing tooth during mastication $(1,9)$. Chlorhexidine oral rinse helps to maintain hygiene. Patient-compliance is important for oral hygiene and to minimize tooth movement.

Dental ankylosis is rare. It is calcified PDL and may occur in traumatized or avulsed teeth that are replanted in the socket $(10,11)$. This can be the result of the removal of a tooth and reseating the tooth in the socket. Although an uncommon outcome, ankylosis is possible. The patient should be informed of this possibility. Nonetheless, securing a diagnosis of ankylosis may be difficult even with cone beam computerized tomography $(\mathrm{CBCT})(11)$.

\section{CONCLUSIONS}

Successful immediate replantation of compromised teeth may depend on several factors: atraumatic removal, presence of 4 rigid bone walls for stability and accompanying vascular supply, occlusal reduction for protection from occlusal forces, antibiotic coverage, a protective brace to minimize tooth micromovement and patient dietary compliance. These parameters are not proven and need validation through research and clinical trials.

\section{INFORMED CONSENT}

A signed informed consent was obtained from the patient.

\section{CONFLICT OF INTEREST}

The author confirms that he has no conflict of interest financial, academic or political. 


\section{REFERENCES}

1. Plotino G, Abella Sans F, Duggal MS, Grande NM, Krastl G, Nagendrababu V, Gambarini G. European Society of Endodontology position statement: Surgical extrusion, intentional replantation and tooth autotransplantation: European Society of Endodontology developed by. Int Endod J. 2021 May;54(5):655-659.

2. Ahmed HM, Hashem AA. Accessory roots and root canals in human anterior teeth: a review and clinical considerations. Int Endod J. 2016 Aug;49(8):724-736.

3. Maru V, Dixit U, Patil RSB, Parekh R. Cytotoxicity and Bioactivity of Mineral Trioxide Aggregate and Bioactive Endodontic Type Cements: A Systematic Review. Int J Clin Pediatr Dent. 2021 Jan-Feb;14(1):30-39.

4. Wang MC, Yeh LY, Shih WY, Li WC, Chang KW, Lin SC. Portland cement induces human periodontal ligament cells to differentiate by upregulating miR-146a. J Formos Med Assoc. 2018 Apr;117(4):308315 .

5. Mehrabi F, Djemal S. International Association for Dental Traumatology guideline updates. Br Dent J. 2021 May;230(10):671-675.

6. Brunet-Llobet L, Lahor-Soler E, Miranda-Rius J. Replantation of an avulsed tooth after one day of storage in adverse extraoral dry conditions: Acceptable outcome after a 10-year follow-up. Quintessence Int. 2018;49(1):25-31.

7. Mittmann CW, Kostka E, Ballout H, Preus M, Preissner R, Karaman M, Preissner S. Outcome of revascularization therapy in traumatized immature incisors. BMC Oral Health. 2020 Jul 14;20(1):207217.

8. Flanagan D. The bis-acryl stent. J Oral Implantol. 2013 Feb;39(1):69-72.

9. Flanagan D. Diet and Implant Complications. J Oral Implantol. 2016 Jun;42(3):305-310.

10. LeBlanc AR, Reisz RR, Brink KS, Abdala F. Mineralized periodontia in extinct relatives of mammals shed light on the evolutionary history of mineral homeostasis in periodontal tissue maintenance. J Clin Periodontol. 2016 Apr;43(4):323-332.

11. Ducommun F, Bornstein MM, Bosshardt D, Katsaros C, Dula K. Diagnosis of tooth ankylosis using panoramic views, cone beam computed tomography, and histological data: a retrospective observational case series study. Eur J Orthod. 2018 May 25;40(3):231-238.

\section{Hosted file}

ARTICLE-InHandApocFIGs.pptx available at https://authorea.com/users/330645/articles/542269extraction-and-replantation-of-a-peri-apically-infected-tooth

Hosted file

ARTICLE-In-HandFIGs.docx available at https://authorea.com/users/330645/articles/542269-

extraction-and-replantation-of-a-peri-apically-infected-tooth 